\section{Year Mortality}

Severe COPD or respiratory failure Yes

No

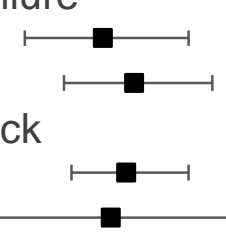

$\operatorname{RR}[95 \% \mathrm{Cl}]$

Congestive heart failure or shock

Yes

No

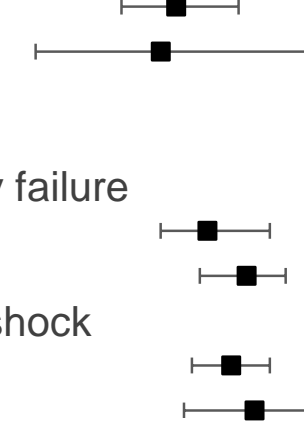

Overall Mortality

Severe COPD or respiratory failure

Yes

No

Congestive heart failure or shock

Yes

Major Adverse Cardiac Events in 1 Year

Severe COPD or respiratory failure

Yes

No

CHF or shock

Yes

No

$\longmapsto$

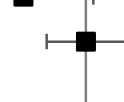

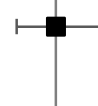

$\square$

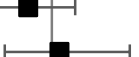

Obstructive Lung Diseases

Severe COPD or respiratory failure

Yes

No

Congestive heart failure or shock

Yes

No
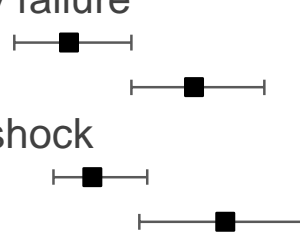

\section{Respiratory Diseases}

Severe COPD or respiratory failure

Yes

No

Congestive heart failure or shock Yes

No
$0.78[0.68,0.89]$

$0.82[0.73,0.92]$

$0.81[0.74,0.89]$

$0.79[0.63,0.98]$

$0.85[0.79,0.93]$

$0.90[0.84,0.95]$

$0.88[0.83,0.93]$

$0.91[0.82,1.00]$

$0.92[0.85,1.01]$ $1.00[0.95,1.06]$

$0.97[0.92,1.03]$

$1.01[0.94,1.10]$

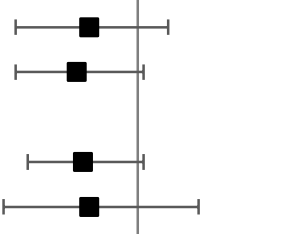

$0.92[0.80,1.05]$

$0.90[0.80,1.01]$

$0.91[0.82,1.01]$

$0.92[0.78,1.10]$

$.09[0.94,1.27]$

$1.00[0.90,1.11]$

$1.02[0.91,1.13]$

$0.99[0.85,1.14]$

$0.57[0.48,0.68]$

$0.83[0.68,1.02]$

$0.83[0.75,0.92]$

$0.70[0.65,0.77]$ *

$0.87[0.76,1.01]$

$0.66[0.56,0.77]$

$0.71[0.55,0.90]$

$0.79[0.69,0.90]$ *

$0.97[0.84,1.11]$

$0.93[0.87,0.99]$

$0.88[0.83,0.93]$

$0.92[0.84,1.02]$

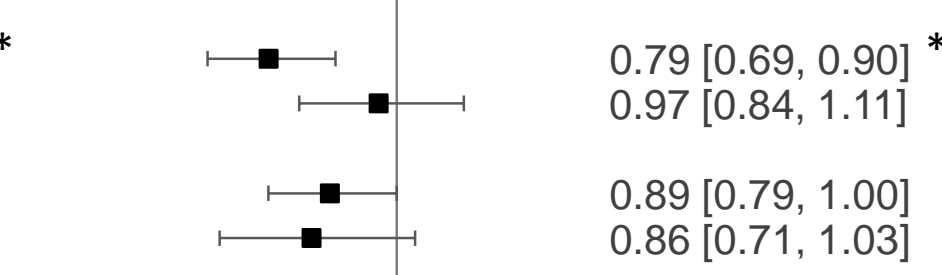

$0.86[0.71,1.03]$

$0.4 \quad 0.6$

0.8

1.2

1.4

1.60 .4

Control $\beta$-blockers

0.8

\title{
Favor $\beta$-blockers
}

